established bone metastases - for management of pain and prevention of pathological fracture. The 2016 statement included recommendations that the use of these highly effective anti-resorptive medications be used in both pre- and post-menopausal women and, crucially, for the prevention of cancer treatment induced bone loss (CBITL) as well as prevention of bone metastases. It is particularly noteworthy that the recommendations mean a significant number of patients will receive anti-resorptive medication concomitantly with systemic chemotherapy.

This sea change of indications for antiresorptives will produce a large number of young patients who are at relatively high risk of developing MRONJ. Dr Tanna and co-authors correctly assert that education of primary care practitioners is important for effective management of patients who have taken anti-resorptive medications. We would like to suggest that communication and coordination between specialist oncology services, patients and primary care dentists is also of paramount importance in order to minimise adverse effects on this group of patients.

C. McKechnie, A. McKechnie, by email

1. Tanna N, Steel C, Stagnell S, Bailey E. Awareness of medication related osteonecrosis of the jaws (MRONJ) amongst general dental practitioners. Br Dent J 2017; 222: 121-125.

2. NICE. 6 -year surveillance 2015 - Early and locally advanced breast cancer. 2013. NICE guideline CG80. 2015 Available at: https://pathways. nice.org.uk/pathways/early-and-locally-advanced-breast-cancer\#path=view\%3A/pathways/ early-and-locally-advanced-breast-cancer/adjuvant-therapy-for-early-and-locally-advanced-breast-cancer. xml\&content=view-node\%3Anodes-assessment-andtreatment-of-bone-loss (accessed 20 February 2017).

3. Hadji P, Coleman R E, Wilson C et al. Adjuvant bisphosphonates in early breast cancer: consensus guidance for clinical practice from a European Panel. Ann Oncol 2016; 27: 379-390.

DOI: $10.1038 /$ sj.bdj.2017.337

\section{Water fluoridation}

\section{There is no evidence}

Sir, Drs Connett ${ }^{1}$ and Osmunson ${ }^{2}$ continue to bang their anti-fluoridation drum.

Most recently they claim that fluoride is a neurotoxin with the implication that this will lead to neurological defects and reduced IQ in children. They often cite studies in rats and a few studies in China of children in rural areas exposed to high levels of fluoride naturally present in water which in some cases is further contaminated by arsenic. A study more relevant to community water fluoridation (CWF) was recently published by Broadbent et al. ${ }^{3}$ They followed up almost
1,000 subjects in New Zealand for over 38 years. Their findings do not support the assertion that fluoride in the context of CWF is neurotoxic or linked to reduced IQ.

Recent reviews of human studies commissioned jointly by the Royal Society of New Zealand and the Prime Minister's Chief Science Advisor ${ }^{4}$ and a second by the Australian Health and Medical Research Council ${ }^{5}$ are quite clear: there is no evidence linking community water fluoridation with neurological defects or reduced IQ. Professionals need to look at these reports and decide whom they prefer to trust.

J. F. Beal, Leeds

M. Lennon, Cheshire

1. Connett P. Is fluoride chemophobia? Br Dent J 2017; 222: 323-324.

2. Osmunson W. Like a knee in the gut. Br Dent J 2017; 222: 324.

3. Broadbent J M, Thomson W M, Ramrakha S et al. Com munity water fluoridation and intelligence: prospective study in New Zealand. Am J Public Health 2015; 105: 72-76.

4. Royal Society of New Zealand and the Office of the Prime Minister's Chief Science Advisor. Health effects of water fluoridation: A review of the scientific evidence. August 2014. Available at: http://royalsociety.org.nz/ expert-advice/papers/yr2014/health-effects-of-water-fluoridation/ (accessed March 2017).

5. Australian Government National Health and Medical Research Council. Draft Information Paper: Effects of water fluoridation on dental and other health outcomes. September 2016.

DOI: $10.1038 /$ sj.bdj.2017.338

\section{Endorsed effectiveness}

Sir, I note the recent letters to the editor from the Fluoride Action Network (FAN) purporting to show the dangers of water fluoridation. ${ }^{1,2}$ Unfortunately, FAN has a long history of twisting the evidence base on fluoridation until it squeals. In 2002 the Irish Forum on Fluoridation described FAN Director Dr Paul Connett's submission as '...[failing] to conform to any generally accepted principles for assembling, evaluating and interpreting medical research. There is no explicit statement of the questions being addressed; no systematic search for pertinent research; no use of $a$ priori selection criteria to separate relevant from irrelevant research; no critical appraisal of studies to determine their validity and no integration of evidence based on sources of evidence, research design, direction and magnitude of clinical outcomes, coherence and precision. No conclusions can or should be drawn from this poor quality document.

Similarly, FAN's recent detailed submission to the US Environmental Protection Agency (EPA) alleging that fluoridated drinking water was neurotoxic was debunked in great detail, with the EPA describing its far-fetched claims as scientifically indefensible.

High quality systematic reviews continue to endorse the effectiveness and safety of water fluoridation.

M. Foley, Director of Research and Advocacy, Metro North Oral Health Services

1. Connett P. Is fluoride chemophobia? Br Dent J 2017; 222: 323-324.

2. Osmunson W. Like a knee in the gut. Br Dent J 2017; 222: 324.

DOI: 10.1038/sj.bdj.2017.339

\section{Orthodontics}

\section{Link with obesity}

Sir, the excellent study done by Professor Martyn Cobourne and colleagues shows that obesity can affect the oral tissues and this can have effects on orthodontic tooth movement in adolescents. ${ }^{1} \mathrm{~A}$ recent study has mentioned that the probability of meeting the global obesity target is almost impossible. ${ }^{2}$ By 2025 global obesity prevalence in men and women will reach $18 \%$ and $21 \%$ respectively.

Adolescents and adults with an increased BMI may need a longer duration of treatment, with more appointments due to less co-operation and tooth movement. ${ }^{3}$ Due to the increase in global obesity more adolescents and adults may require orthodontic treatment and this will add to the economic burden in both developed and developing countries.

Mahantayya V. Math, Yashoda R. Kattimani, Navi Mumbai, Maharashtra State, India

1. Saloom H F, Papageorgiou S N, Carpenter G H, Cobourne M T. Impact of obesity on orthodontic tooth movement in adolescents. J Dent Res 2017; 22034516688448.

2. NCD Risk Factor Collaboration (NCD-RisC), Trends in adult body-mass index in 200 countries from 1975 to 2014: A pooled analysis of 1698 population-based measurement studies with 19.2 million participants. Lancet 2016; 387: 1377-1396.

3. Von Bremen J, Lorenz N, Ruf S. Impact of body mass index on oral health during orthodontic treatment: an explorative pilot study. Eur J Orthod 2016; 38: 386-392. DOI: $10.1038 /$ sj.bdj.2017.340

\section{Fitness to practise}

\section{A question of reputation}

Sir, we would like to respond to

A. C. L. Holden's critique ${ }^{1}$ of our recent paper. ${ }^{2}$ We welcome debate on the issue of regulatory scope but we disagree with the characterisation of our position. We do believe behaviour outside the clinic can have a bearing upon professional practice. Our 
contention is that judgements should be made on whether patient wellbeing is threatened, not on the reputation of the profession. In the Armstrong case the reprimand was given because her actions, '...placed the profession at real risk of being brought into disrepute. ${ }^{3}$ However, she had not treated patients badly and the Committee did not believe she would do so in the future. If the Committee had found that she was likely to treat her patients in a sectarian manner they would have been right to take action. However, they did not. The reprimand was seemingly intended to show the regulator disapproves of such conduct.

We are concerned that too much is expected of dental professionals. The ninth standard of Standards for the dental team is to, 'Make sure your personal behaviour maintains patients' confidence in you and the dental profession. ${ }^{4}$ We believe that this standard needs to be questioned. The implication is that the dental professional is judged by how it is thought the public will perceive their personal behaviour.

We do not see professionalism as a 'temporally-based concept ${ }^{\text {' }}$ but rather as a situationally-based concept. It applies in a professional situation, such as interacting with a patient, but not in others, such as in personal, sexual relationships. Holden agrees with us on this fundamental point when he acknowledges that the nurse having an affair would not be impaired to practice, '... as infidelity in a relationship in itself is very unlikely to affect patient care.' ${ }^{1}$ Our point is not that an affair is morally equivalent to posting hateful material, but that judgements of personal behaviour should be based on relevance to that professional's practice rather than the reputation of the profession. Akin to Holden, we would greatly welcome further responses to develop this debate.

\section{P. Affleck, K. Macnish, by email}

1. Holden A C L. Paradise Lost; the reputation of the dental profession and regulatory scope. Br Dent J 2017; 222: 239-241.

2. Affleck P, Macnish K. Should 'fitness to practise' include safeguarding the reputation of the profession? Br Dent $J$ 2016; 221: 545-546.

3. General Dental Council. Professional Conduct Committee March 2016.

4. General Dental Council. Standards for the dental team 2013. Available at: https://gdc-uk.org/professionals/ standards/team (accessed March 2017).

DOI: $10.1038 /$ sj.bdj.2017.341

\section{OMFS}

\section{GA rights}

Sir, the Hong and Baker paper ${ }^{1}$ in relation to dental extractions under general anaesthetic (DGA) was particularly interesting. It highlights many of the challenges dentists working in a hospital setting face on a daily basis.

One challenge which appears to be increasingly prevalent is the management of patient expectations in relation to DGA. I agree wholeheartedly with the authors that clinical need in relation to DGA is not clearly defined and often interpreted differently amongst practitioners. The differing interpretations frequently become apparent in patient referrals to the hospital setting. A substantial number of patients are referred each year for extraction of teeth under GA often citing anxiety, difficulty of extraction, or number of teeth to be extracted as the reason for necessity of GA. Contrary to the authors report my experience is that referrals for failed extraction attempts under LA are rare.

In some instances there is certainly a clear clinical need for DGA but in a substantial number I believe the expectation of the patient for DGA is often a significant factor for referral in the first instance. Many patients referred for treatment under GA have previously undergone restoration and in some cases extraction of teeth under LA. The raised expectation for GA, whether related to anxiety or not, is often compounded by the GDP assessment and treatment plan for DGA. Additionally, the referral to a hospital setting only strengthens the patient's belief that treatment must be 'too difficult' to be carried out under LA.

Having seen adult patients undergo 'simple' extractions under GA on more than one occasion over a period of years, I do wonder whether we are missing the bigger picture. With no apparent intervention or management of these patient's anxieties in the interim between each GA treatment, it has become clear that a holistic approach to patient care is often not taking place. Is it not our place as clinicians to not only deal with the need for treatment but also the management of patient attitude and anxiety? We regularly carry this out in relation to oral hygiene and in a similar vein should apply the same emphasis to managing patient expectation and any underlying causes to potentially severe anxiety.

I am aware that the current NHS system in dentistry does not necessarily encourage or allow for any significant time spent on behaviour management. However, with the problem continuing to worsen it may be something which needs to be addressed not only to improve patient care but also relieve strain on NHS hospital beds and theatres which are already stretched beyond their limits.

\section{Causey, Kettering}

1. Hong B, Baker A. General anaesthetic service for adult dental extractions: an 'A La carte Menu'? Survey results. Br Dent J 2017; 222: 261-267.

DOI: 10.1038/sj.bdj.2017.342 